\title{
A RELEVÂNCIA DE UMA PRÁTICA PEDAGÓGICA INOVADORA NO ENSINO DE HISTÓRIA NA ESCOLA DE ENSINO MÉDIO DR. DJALMA DA CUNHA BATISTA
}

\section{ARTIGO ORIGINAL}

FROTA, Maria Rosineia da Silva ${ }^{1}$

FROTA, Maria Rosineia da Silva. A relevância de uma prática pedagógica inovadora no ensino de história na Escola de Ensino Médio Dr. Djalma da Cunha Batista. Revista Científica Multidisciplinar Núcleo do Conhecimento. Ano 04, Ed. 07, Vol. 13, pp. 103-113. Julho de 2019. ISSN: 2448-0959

\section{RESUMO}

O Presente originou-se de uma pesquisa a qual objetivava verificar a prática dos docentes do ensino de história da escola Dr. Djalma da Cunha Batista, a qual versa sobre as potencialidades de uma metodologia inovadora na docência do ensino de história, buscando fundamentação para tal problematização em autores como: Vera Candal, Libâneo, Demerval Saviane e outros. O tipo de pesquisa é caraterizada como descritiva, e a abordagem foi quantitativa, fazendo uso de questionário e analisando os dados através de tabulação e gráfico estatístico. Foi verificado que os docentes que atuam na referida instituição de ensino fazem uso de uma metodologia inovadora e diferenciada e não apenas voltada para transposição didática; eles trabalham com projetos didáticos pensados, elaborados e executados junto à comunidade estudantil, os quais buscam retratar na prática os conteúdos propostos no plano de curso da disciplina. Realizam com isso uma associação e interação entre teoria e prática no tocante aos conteúdos, favorecendo de forma positiva a assimilação de conteúdos e uma aprendizagem pautada em bons resultados. Os dados estatísticos de rendimento

${ }^{1}$ Mestre em Ciência da Educação; Especialista em Gestão e Planejamento para Educação Básica- UVG/MG; Licenciada em História. 
escolar demonstram que a disciplina de história não se enquadra no quadro de disciplinas em nível crítico de aprendizagem, ou seja, com nível elevado de reprovação ou discentes com média abaixo do padrão de qualidade exigido, fato que demonstra que a metodologia aplicada pelos docentes da instituição do ensino de história em sua prática docente é adequada. Também foi demonstrado mediante dados coletados junto a equipe gestora, administrativa, pedagógica e discentes que os referidos docentes possuem responsabilidade e bom desempenho no exercício de suas funções profissionais. Sendo assim, a hipótese levantada previamente ao se elaborar projeto de pesquisa foi confirmada e afirma-se como positiva, ou seja, o uso de uma metodologia inovadora na prática docente do ensino de história é fundamental no resultado final da aprendizagem, exercendo influência relevante e significativa na prática docente.

Palavras-Chave: metodologia, prática inovadora, docente, história.

\section{INTRODUÇÃO}

O trabalho ora exposto, objetivou sistematizar dentro de uma perspectiva diagnóstica a realização dos propósitos aqui apresentados, como ainda nortear todo trabalho no ambiente da pesquisa a que se propõe. A literatura e a historiografia em prol de uma compreensão do ensino de história volta-se a formação de cidadãos críticos utilizando uma metodologia diferenciada. Para tanto, fizemos uso dos autores Vera Candau (1999), Libânio (1985), Demerval Saviane (1985), Vaquez (1977), ainda a luz de outros autores como Isabel Leles (1989) e sua pesquisa acadêmica dos Parâmetros Curriculares Nacionais- PCNs e Orientação para o Ensino Médio voltando-se à docência do ensino de história.

O problema nasceu da necessidade e preocupação de se verificar se os docentes da única escola de ensino médio da cidade de Tarauacá no estado do Acre, faziam na época, uso de uma metodologia diferenciada em sua prática docente diária. E, junto aos mesmos contribuir observando e avaliando se ocorria ou não utilização de uma metodologia diferenciada na prática docente diária, para então propor se necessário 
aos referidos apresentando os dados coletados a necessidade de adequação de uma metodologia modificada, visando melhoria da aprendizagem e melhoramento da qualidade de ensino da instituição escolar tendo seu quadro de docentes do ensino de história avaliado.

O problema desta pesquisa foi: Como é a metodologia utilizada na prática docente do ensino de história, na escola de Ensino Médio Dr. Djalma da Cunha Batista, no município de Tarauacá no Acre. A hipótese que orientou o trabalho foi: A prática docente do ensino de História, na escola de Ensino Médio Dr. Djalma da Cunha Batista, no município de Tarauacá no Acre, utiliza uma metodologia diferenciada e atualizada, orientada a facilitar a formação do cidadão consciente e crítico. Tinha como objetivo Geral: Verificar a metodologia utilizada na prática pedagógica do ensino de história na escola de Ensino Médio Dr. Djalma da Cunha Batista, no município de Tarauacá no estado do Acre. E específicos:

- Caracterizar o tipo de prática pedagógica utilizada pelos professores de História na escola;

- Identificar as metodologias utilizadas pelos professores;

- Determinar o grau de responsabilidade e compromisso do docente de História na formação do cidadão crítico e consciente do seu papel na sociedade.

Justificava-se na ideia de que, trabalhar na educação no Acre é revirar a História da Educação no Acre, e adentrar a historiografia da Educação no Brasil, é perceber o quanto o Acre precisa de aperfeiçoamento no referido assunto. Partindo desses pressupostos é que nos despertamos e comprometemos a tentar aprimorar os registros da historiografia no Acre e poder de forma ousada com isso contribuir um pouco com a Educação do Estado no tocante à fonte de pesquisa. Como ainda contribuir para tomada de consciência de cada cidadão acreano que atua na docência do ensino de história para o quesito cultura e sociedade e através deste processo poder agir e interagir com o crescimento econômico e político do Estado e consequentemente deixar registros positivos na História da Educação Acreana, pois falar de Educação não é apenas falar, mas intervir no meio social e histórico. A 
proposta a qual foi elaborada naquele momento, objetivava traçar diretrizes para uma linha de pesquisa voltada a oferecer aprimoramento no sentido de atentar os docentes da necessidade de se utilizar uma metodologia diferenciada na docência do ensino de história. Como ainda servir de subsídio de pesquisa para futuros pesquisadores que por ventura venham a despertar para o interesse e desejo de desenvolver pesquisa no campo ora mencionado.

\section{METODOLOGIA}

A metodologia desenvolvida neste trabalho compreendeu uma revisão da literatura sobre o tema proposto na área do ensino de história, e em seguida foi realizada uma pesquisa de campo sobre o a importância de uma metodologia diferenciada de acordo com o tema proposto. $O$ trabalho foi desenvolvido nas seguintes fazes: análise de acervos bibliográficos, pesquisa in loco, verificação de situações reais e exposição de dados coletados em um informe final, através de dissertação acerca do assunto. $O$ qual por sua vez estará distribuído na seguinte estrutura: marco teórico, marco metodológico, resultados e conclusão.

No marco teórico, foram trabalhados alguns teóricos ligados a prática docente, como ainda foi feito um recorte de pontos de vista de alguns profissionais com relação ao tema proposto, analisando a relevância da utilização de uma metodologia diferenciada na formação de um cidadão crítico consciente e contextualizado na sociedade vigente. Como ainda está contido no mesmo toda a base legal do ensino de história fundamentando-se na Lei de Diretrizes e Bases (LDB).

No capítulo 2 a pesquisa procurou analisar a realidade escolar da Escola Dr. Djalma da Cunha Batista, realidade esta, que tornou possível fazer um contraste entre o que foi apresentado na parte teórica deste trabalho ora apresentado e a realidade pesquisada in loco na escola retro mencionada. Para isso, foi realizada uma pesquisa de campo, numa abordagem quantitativa e qualitativa na escola retro mencionada, e os dados recolhidos foram analisados a luz dos teóricos para produzir um informe final. A pesquisa tinha como objetivo geral: analisar a metodologia diferenciada e 
inovadora utilizada na prática pedagógica do ensino de história na escola de Ensino Médio Dr. Djalma da Cunha Batista, no município de Tarauacá no estado do Acre, orientada a formar cidadãos conscientes e críticos. E objetivos específicos foram:

- Caracterizar o tipo de prática pedagógica utilizada pelos professores de História na escola;

- Identificar as metodologias utilizadas pelos professores;

- Determinar o grau de responsabilidade e compromisso do docente de História na formação do cidadão crítico e consciente do seu papel na sociedade.

Tendo como fundamentação teórica, Segundo, Isabel Alice Lelis (2000), as matrizes, ou seja, as fontes sempre estarão voltadas a apresentar a valorização da prática docente, como um lugar de troca de experiência, o qual o ambiente, o espaço onde ocorre tal atividade deve ser um espaço harmônico, envolvente e preocupado com a realidade social vigente, na qual o discente receptor de informação deverá está sentindo-se parte do universo social. Sendo assim, foi realizada pesquisa quantitativa e qualitativa nos três (03) turnos os quais a escola tem funcionamento.

\section{CONCLUSÃO}

No currículo do docente do ensino de história reza que o mesmo deve sempre valorizar a prática pedagógica docente, como lugar de troca de experiência, o qual o ambiente, o espaço onde ocorre tal atividade, deve ser um espaço harmônico, envolvente e preocupado com a realidade social vigente, na qual o discente receptor de informação deve sentir-se parte do universo social, opondo-se ao velho modelo curricular existente no Brasil na década de 70 , no qual a escola através da prática docente voltava-se simplesmente a reproduzir indivíduos, mecanizados e controlados pela sociedade vigente, período no qual a escola atuava meramente como reprodutora de classes sociais. (BASSO, 1998).

O docente do ensino de história deve possuir ciência da relevância de seu trabalho na construção de uma sociedade mais justa, igualitária e tal propósito só será possível 
se ele voltar sua prática docente na formação de cidadãos críticos e conscientes. (BONAMINO, 1989)

Hoje os profissionais da sociedade educacional brasileira que atuam no ensino médio dispõem de recursos como os Parâmetros Curriculares Nacionais- PCNs e as Orientações para o Ensino Médio, nos quais reza que os referidos devem tratar os conteúdos de forma a inserir a realidade social dando margem e abertura para ele atuar como agente construtor desta sociedade justa e igualitária, e para se criar esse espaço o docente do ensino de história deve sim ter uma boa fundamentação teórica, mas a mesma sempre deverá vir acompanhada de uma boa articulação com a prática e para isso ocorrer, ele deve fazer uso de instrumentos que viabilizem essa articulação entre teoria e prática. Deve acima de tudo está constantemente se atualizando quanto a novas metodologias e transposições didáticas, a fim de tornar as aulas mais agradáveis, atrativas e interessantes. Porém ressalto, de nada adiantaria se tal docente não fizer uso de responsabilidade e compromisso com a árdua causa educacional a que se propõe, atentando-se sempre aos seguintes indicadores: pontualidade, assiduidade, domínio de sala, fundamentação teórica em consonância com a prática. (CANDAU; LELIS, 1999).

Nesse sentido, a dissertação a qual originou este, versa sobre as potencialidades da utilização de uma metodologia diferenciada na docência do ensino de história. Fundamenta-se em autores que contribui para problematizar tal assunto, como Vera Candal, Libânio, Demerval Saviane, Vaquez entre outros, ainda a luz de outros autores como Isabel Leles em sua pesquisa acadêmica, dos Parâmetros Curriculares Nacionais- PCNs e Orientação para o Ensino Médio voltando-se à docência do ensino de história, nos pressupostos de uma educação humanizadora, inserida em um espaço no qual professor e aluno motivados trocando experiências na construção do conhecimento, sendo que nesta troca de experiências, o docente atua como mediador de conhecimentos fazendo uso de uma metodologia diferenciada, ou seja, indo além das "antigas" práticas pedagógicas utilizadas como alternativa principal dentro de um contexto no qual a educação brasileira ficou conhecida como tradicional. $\mathrm{O}$ trabalho ora apresentado objetivou construir uma pequena iniciação científica da relevância de 
uma prática pedagógica docente fazendo uso de uma metodologia diferenciada. Nos propomos neste, viabilizar chamando atenção para discursão da necessidade do docente atuante no sistema educacional vigente atentar-se para uma prática docente mais atrativa e envolvente na construção do conhecimento.

A pesquisa científica apresentada tinha como objetivo geral investigar se a metodologia utilizada na prática docente do ensino de História na Escola de Ensino Médio Dr. Djalma da Cunha Batista, no município de Tarauacá no estado do Acre tem se voltado a formar cidadãos conscientes e para tanto, foi analisado o ambiente escolar, voltando-se para o quesito metodologia utilizada pelos docentes em sua prática diária, afim de com a referida afirmar ou negar a hipótese outrora posta em questão: a prática docente do ensino de história, na escola de Ensino Médio Dr. Djalma da Cunha Batista, no município de Tarauacá no Acre, utiliza uma metodologia diferenciada e atualizada orientada a facilitar a formação do cidadão reflexivo e crítico. A pesquisa desenvolveu-se em três fases distintas: acervos bibliográficos, pesquisa in loco, na qual nesta fase foi possível realizar verificação de situações reais. Por fim houve a exposição dos referidos dados coletados no informe final ora apresentado na referida dissertação. Relevante enfatizar que na pesquisa in loco, os docentes foram avaliados mediante dois critérios Prática Pedagógica. Compromisso e Responsabilidade na docência do ensino de História, sendo estabelecido para o critério Prática Pedagógica os indicadores: articulação entre teoria e prática, ciência com relação à relevância de seu trabalho junto a sociedade vigente, atualização quanto ao uso de nova metodologia e transposição didática. Quanto ao critério responsabilidade e compromisso foram analisados os seguintes indicadores: aulas teóricas, aulas práticas, assiduidade, pontualidade e domínio de sala de aula. Para o critério Prática Pedagógica foi estabelecido um parâmetro de $80 \%$ dos docentes e para o critério Responsabilidade e Compromisso foi estabelecido um Parâmetro de $60 \%$ dos docentes. Quanto às fontes utilizadas para obtenção das amostras coletadas com relação a variável docente, foram as seguintes: Equipe gestora (gestor, coordenação de ensino e coordenação administrativa), Equipe pedagógica (coordenação pedagógica) dos três turnos nos quais funciona a instituição de ensino 
avaliada e discentes do $3^{\circ}$ ano de Formação Integral, os quais por sua vez foram selecionados por já estarem no último ano e já terem havido passado pelas séries e respectivos docentes do ensino de história nos anos anteriores. Quanto à técnica utilizada para obtenção dos dados foi enquete/ entrevista, tendo como instrumento, questionário e guia de entrevista junto às respectivas fontes utilizadas, como ainda tivemos como técnica análise documental como evidência lista de frequência e canhotos (contendo notas e menções alcançados) dos discentes que participaram da pesquisa ora apresentada. Esta por sua vez mista, ou seja, quantitativa e qualitativa a luz do Sampiere no tocante a metodologia apresentada na respectiva dissertação. Ainda, no tocante a pesquisa as amostras foram selecionadas de forma aleatória e estratificada, aleatória por conta de todos os estudantes do $3^{\circ}$ ano terem tido a mesma oportunidade de participar e conglomerada, uma vez que, foi coletada amostra de vários seguimentos da instituição, sendo entrevistado uma amostra de 112 de uma população de 1120 discentes, ou seja, 10\% da população do corpo discentes e 100\% da equipe gestora da Instituição Educacional.

E após, minuciosa avaliação realizada a variável atuação do docente no ensino de história, foi possível detectar que mediante dados coletados junto às fontes que a hipótese foi confirmada, ou seja, a utilização de uma metodologia diferenciada na prática docente do ensino de história facilita a melhor compreensão por parte do educando, tal afirmação é justificada a luz do marco teórico e comprovada na pesquisa in loco e tabulada neste informe. Tendo em vista que a pesquisa foi realizada em segmentos diferentes da instituição foi possível realizar uma contratação entre as informações coletadas com referidos: Equipe gestora \& Corpo discente, os parâmetros propostos foram alcançados em ambos os segmentos. Ficando conforme consta na tabulação apresentada no geral em uma média de $80 \%$ a $100 \%$ no critério Prática Pedagógica e $60 \%$ a $76 \%$ nos critérios responsabilidade e compromisso. Fato que torna possível afirmar que os objetivos propostos foram alcançados, ou seja, que os docentes que no ensino de História da instituição avaliada tem voltado sua prática pedagógica a formação de cidadãos críticos conscientes dentro da sociedade vigente, fazendo uso de uma metodologia diferenciada, a qual por sua vez vai além do livro 
didático e do quadro de giz, mas trabalham com métodos diferenciados em atividades práticas como adotam inclusive a elaboração e execução junto aos discentes de vários projetos didáticos envolvendo os diversos conteúdos proposto no plano de curso adotado pela disciplina conforme constam alguns nos anexos. Porém é importante enfatizar que quanto ao quesito pontualidade a qual compõe o critério responsabilidade e compromisso realizado junto aos discentes, apenas $57 \%$ dos docentes segundo informação dos referidos cumprem tal quesito.

Sendo assim com relação ao não cumprimento do item avaliado sugerimos a equipe gestora uma campanha na escola no tocante a chamar atenção para este item pontualidade. A sugestão apresentada objetiva evitar que os docentes venham a ter prejuízos quanto ao padrão de qualidade escolar no critério responsabilidade e compromisso, os quais por sua vez são de suma importância para o florescimento e permanência de uma boa imagem da instituição avaliada.

Em suma, enfatizamos que os docentes do ensino de História da Escola de Ensino Médio Dr. Djalma da Cunha Batista fazem uso de uma metodologia diferenciada em sua prática pedagógica diária, voltando seu trabalho a formação de cidadãos críticos e conscientes da sociedade vigente e, tal fato e de uso das evidências apresentadas neste é possível reafirma a hipótese posta em questão no início da avaliação ora apresentada, ou seja, a utilização de uma metodologia diferenciada no Ensino de História facilita a formação do cidadão reflexivo e crítico. Como ainda, enfatizamos a ciência que o trabalho ora apresentado longe está de ser definido como pronto e acabado, fato que nos faz sugerir a futuro pesquisadores o despertar do interesse por tal tema, e quando isso acontecer esperamos poder contribuir como subsídio para tal produção acadêmica e científica.

A partir dos resultados desta pesquisa, recomenda-se que próximas pesquisas sejam desenvolvidas nesta linha com os egressos da escola, a fim de comprovar a qualidade da formação do cidadão reflexivo e crítico na sua atuação posterior na sociedade. $E$ que também sejam desenvolvidas pesquisas sobre a relevância da presença ativa da 
família e da comunidade na vida escolar dos discentes, e a sua influência na formação cidadã dos educandos.

\section{REFERENCIAS BIBLIOGRÁFICAS}

BASSO. Ytacy Salgado. Significado e sentido do trabalho docente. vol.19 n.44 Campinas . 1998.

BONAMINO, A.M.C. O Pensamento pedagógico-político de Dermeval Saviani. Até que ponto Gramsci? Dissertação de mestrado em Educação, Departamento de Educação da PUC- Rio, 1989. 211p.

BRASIL. Ministério da Educação. Parâmetros em Ação, Ensino Médio: Ciências Humanas e suas Tecnologias/ secretaria da Educação Média e Tecnológica - MEC; 502 p. SEMTEC, 2002.

BRASIL. Secretaria de Educação Média e Tecnológica . Parâmetros curriculares nacionais: ensino médio/ Ministério da Educação, Secretaria de Educação Média e Tecnológica - MEC; SEMTEC. 360p. : il. Brasília. 2002.

CANDAU, V.M.F. e LELIS, I.A. A relação teoria-prática na formação do educador. In: CANDAU, V.M. F. (org.) Rumo a uma nova didática. 9ª ed. Petrópolis: Vozes, 1999, p. 56-72.

LELIS .Isabel Alice. Do Ensino de Conteúdos aos Saberes do Professor a mudança de Idiomas Pedagógico. 2000.

LELIS, I A. A Formação da professora: Da denúncia ao anúncio. $4^{\text {a }}$ ed. São Paulo: Cortez, 1989. 134 p.

LIBÂNEO, J.C. Democratização da escola pública: A pedagogia crítico-social dos conteúdos. São Paulo: Loyola, 1985, p. 45-56. 
SAVIANI, D.A. Pedagogia histórico-crítica no quadro das tendências da Educação Brasileira. ANDE - Revista da Associação Nacional de Educação no11, São Paulo: Cortez, 1985, p.15-23.

TECNOLOGIAS. Ciências humanas e suas. Secretária de Educação Básica, Ministério da Educação, - vol.3 n 133p: Ministério da Educação,. Brasília 2006.

VAZQUEZ, A.D. Filosofia da praxis. Rio de Janeiro: Paz e Terra, 1977. 454p.

Enviado: Março, 2019.

Aprovado: Julho, 2019. 